\title{
Inappropriate Choice of the Experimental Unit Leads to a Dramatic Overestimation of the Significance of Quantitative Trait Loci for Prepulse Inhibition and Startle Response in Recombinant Congenic Mice
}

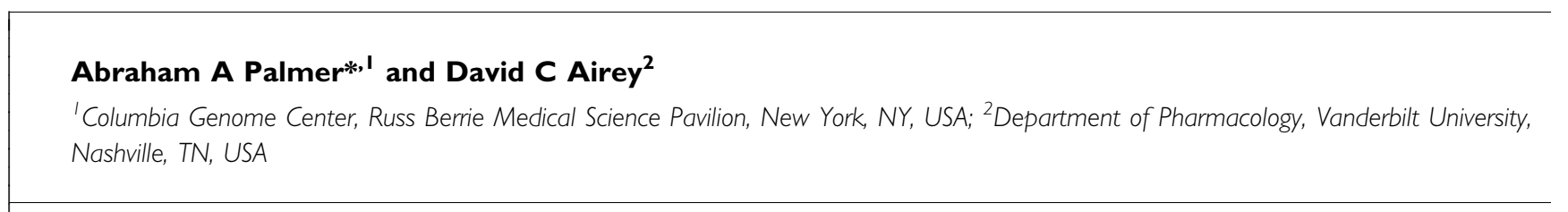

Neuropsychopharmacology (2003) 28, 8 I8. doi:I0.1038/sj.npp. I 300064

Sir

We are writing to express our concern about the statistical methods used in the recent publication by Joober et al (2002) in Neuropsychopharmacology. These authors have used a panel of recombinant congenic (RC) mouse strains, conceptually similar to the more commonly used recombinant inbred (RI) mouse strains, to map quantitative trait loci (QTL) for prepulse inhibition (PPI). Joober et al measured PPI in 10-15 mice from each of 37 inbred strains and analyzed the effect of 625 previously defined genetic markers on this phenotype. The authors state: 'For the QTL analysis, data from all animals, regardless of their genetic background, were entered into a one-way analysis of variance (ANOVA), where the genotype (A/J homozygous coded 1 and $\mathrm{C} 57 \mathrm{BL} / 6 \mathrm{~J}$ coded 2 ) was considered as the grouping factor and ASR or PPI at different prepulse intensities was the dependent variable.' The ANOVA model used by Joober et al incorrectly treats every mouse as an independent observation and thereby uses the mouse, rather than strain, as the experimental unit.

The total variance $(V)$ among RC strains arises from the combination of genetic, environmental, and the interaction of genetic and environmental factors: $V=V(g)+V(e)+V\left(e^{\star} g\right)$. A QTL study seeks to identify the source of $V(g)$ in terms of the contribution of individual marker genotypes. Because all members of a given strain share their entire genome with one another, it is impossible to identify the source of $V(g)$ by considering the variance between members of an individual strain, as the variance between these individuals comes entirely from the $V(e)$ component of the above equation. The unit of analysis to determine the source of $V(g)$ must be the differences

* Corresponding author. Dr AA Palmer, Columbia Genome Center, Unit 109, Russ Berrie Medical Science Pavilion, Room 513, II50 St. Nicholas Ave., New York, NY, USA, E-mail: aap2010@columbia.edu between one or more strains. In general, the experimental unit is the measurement level (strain, not individual mouse) at which the experimental factor (genotype at a given loci) can vary (Anderson, 1990).

An appropriate ANOVA for the presence of QTL is a onefactor model that uses strain means as observations. A more sophisticated approach is a nested one-factor model that nests strain in genotype and constructs an $\mathrm{F}$ ratio of the genotype mean square over the mean square for the nested term. The nested ANOVA uses all observations, accounts for nonindependence of observations within strain, and properly evaluates parameters for each genotype level. The consequences of mistakenly treating observations on mice within strains as independent are quite serious, and can result in false positive rates far in excess of the expected $5 \%$ (Anderson, 1990; Kenny and Judd, 1986; Machlis et al, 1985). A reanalysis that uses an appropriate nested design, or that simply examines the strain means, would yield statistically valid results that would be of greater interest to the field.

\section{REFERENCES}

Anderson B (1990). Methodological Errors in Medical Research. Chapter 13: The Sampling Unit. Blackwell Publishers: Oxford, UK. pp 147-156.

Joober R, Zarate J, Rouleau G, Skamene E, Boksa, P (2002). Provisional mapping of quantitative trait loci modulating the acoustic startle response and prepulse inhibition of acoustic startle. Neuropsychopharmacology, in press (originally published online March 14, 2002, at http://www.acnp.org/citations/ Npp031402268).

Kenny DA, Judd CM (1986). Consequences of violating the independence assumption in analysis of variance. Psychol Bull 99: 422-431.

Machlis L, Dodd PWD, Fentress JC (1985). The pooling fallacy: problems arising when individuals contribute more than one observation to the data set. Z Tierpsychol 68: 201-214. 